\title{
One more step against nanotoxicity: Hierarchical particles designed to antifungal properties
}

\author{
Eva de Lucas-Gil *, José F. Fernández, Fernando Rubio-Marcos \\ Electroceramic Department, Instituto de Cerámica y Vidrio, CSIC, Kelsen 5, 28049 Madrid, Spain
}

\section{H I G H L I G H T S}

- Synthesis of hierarchical ZnO generates flower-like structures by a formation mechanism based on oriented aggregation

- The obtained ZnO hierarchical structure improves the antifungal activity

- The improved antifungal activity is due to low participation of chemical interactions favouring a purely physical mechanism

\section{G R A P H I C A L A B S T R A C T}

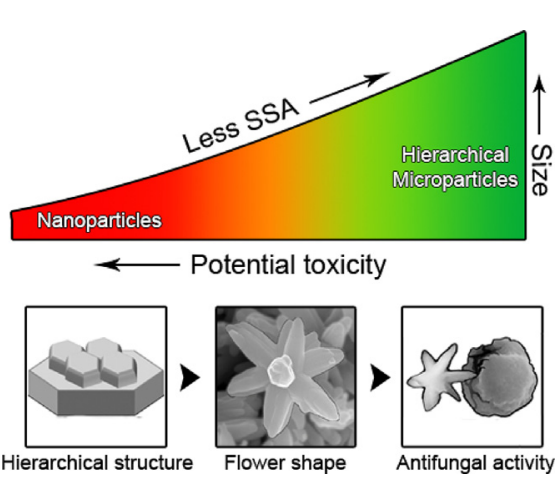

\begin{abstract}
A B S T R A C T
The interest that awakens the $\mathrm{ZnO}$ as material is greatly extended both by its unique properties as by its wide variety of applications. Within these applications, antimicrobial activity is gaining relevance. Especially, the bactericidal activity of $\mathrm{ZnO}$ nanoparticles is outstanding but little is known about antifungal activity. In addition, the recent discussion about the potential toxicity of nanoparticles and their massive use places them in the spotlight. In response to this emerging problem, a simple and general approach to synthesize hierarchical structure of $\mathrm{ZnO}$ is reported. A formation mechanism of these surprising structures is proposed. Moreover, the obtained zinc oxide hierarchical particles improves the antifungal activity towards Aspergillus niger in contrast to ZnO micro or nanoparticles. Due to surprising results, the different action mechanisms of $\mathrm{ZnO}$ hierarchical particles against fungi are studied. Thus, we pose a novel physical mechanism by which $\mathrm{ZnO}$ hierarchical particles achieve excellent fungicidal results.
\end{abstract}

(c) 2017 Elsevier Ltd. All rights reserved.

\section{Introduction}

The great interest in research on $\mathrm{ZnO}$ like smart and versatile material, despite not being a new material, is because of its unique properties and wide range applications. Among its important properties stand out II-VI semiconductor due to a wide band gap energy of $3.37 \mathrm{eV}$ and a large exciton binding energy of $60 \mathrm{meV}[1,2]$. Mainly, zinc oxide

\footnotetext{
* Corresponding author.

E-mail address: elucas@icv.csic.es (E. de Lucas-Gil).
}

presents a hexagonal wurtzite structure at ambient conditions. This unit cell has two lattice parameters, $a=3.250 \AA$ and $c=5.207 \AA$ and belongs to the space group $\mathrm{P}_{3} \mathrm{mc}$ [3].

Another important factor as useful material is the morphological variety. $\mathrm{ZnO}$ has one of the greatest structural collections [4] among all known materials and can be classified in one- (1D), two- (2D) and three-dimensional (3D) structures. Some examples of 1D structure are nanorods [5,6], nanoneedles [7], nanowires [8] and nanobelts [9]. Most common 2D structures are nanosheet [10] and nanopellets [11]. Regard to 3D structures include cauliflower [12], snowflakes [13] and 
nanocages [14] among others. This assortment of morphologies is possible thanks to diversity synthesis processes reported in the literature such as aqueous solution growth, chemical vapour deposition, hydrothermal synthesis, sol-gel method and microwaves assisted synthesis $[15,16]$.

Modulate size and shape of $\mathrm{ZnO}$ structures allows for adapting the product to the intended application. ZnO plays an important role in an extensive range of fields of technology like photocatalysis [17,18], solar cells [12,15], rubber additives, sensors [15,19] and cosmetic [20]. Moreover, $\mathrm{ZnO}$ presents an antimicrobial activity which catches the attention of researchers in recent times. The antimicrobial activity can be broken down into antibacterial and antifungal activity. About antibacterial activity that has been widely reported [21-23], one of the most important factors is the particle size. Yamamoto et al. [24] studied the influence of $\mathrm{ZnO}$ microparticles ( $\mathrm{ZnO} \mathrm{MPs}$ ) on the antibacterial activity, while Padmavathy and Vijayaraghavan [25] reported the antimicrobial behaviour of $\mathrm{ZnO}$ nanoparticles (ZnO NPs) with different particle size, both proved that the antibacterial activity increased with decreasing particle size due to the higher surface area to volume ratio. Applerot et al. [26] confirmed the particle size dependence with efficient antibacterial activity, relating it to reactive oxygen species (ROS) and particle defects. However, antifungal activity has not been intensively studied. Recently, Lipovsky et al. [27] reported the effective antifungal activity of $\mathrm{ZnO}$ nanoparticles compared to micron sized that may be attributed to the reduced size and increase surface area to volume ratio. Meanwhile, Lin's group [28] investigated the effect of $\mathrm{ZnO}$ nanoparticles on fungal growth by SEM and Raman spectroscopy. To date, there are only a few studies about if size plays a relevant role in the antifungal mechanism. Therefore, there is no well-established reaction mechanism yet.

Over the past few years, the potential toxicity of NPs has provoked public and scientific discussions, and attempts to develop generally accepted handling procedures for NPs are under way. More concretely, the common utilization of $\mathrm{ZnO} \mathrm{NPs}$ results in an increasing environmental release (estimated $~ 500$ tons in 2009 in the U.S.) and may lead to adverse health effects [29]. The impact of nanotechnologies on everyday products could be more tremendous than expected. Within the nearly limitless diversity of the nowadays commercialize NPs, some happen to be toxic to biological systems, others are relatively benign, while others confer health benefits [30]. The question that nobody can answer today is related to how the massive use nanoparticles will affect the living organism in a medium-large period? Right now it is mandatory to think of how to avoid or minimize the harmful future impact and to strengthen the enormous benefit that nanoparticles could contribute to the society. Thus, we believe that the solution of the harmful collateral effect of nanotechnology must be addressed by hierarchical nanostructured particles, in which provides the advantages of nanoparticles would be preserved but harmful effect eliminated.

Herein, we pose a strategy for the in situ self-assembly of $\mathrm{ZnO}$ nanoparticles to build "hierarchical structures" with flower shaped, which are favoured by subsequent heat treatments. Using this safe hierarchical structure allows for improved antifungal activity without being required nanoparticles with high surface area to volume ratio and therefore its efficiency of use. To our knowledge these $\mathrm{ZnO}$ hierarchical particles are unique in two properties: size and SSA sufficient to be away from potential toxicity and an improvement of the fungicidal activity based on a physical mechanism.

\section{Experimental section}

\subsection{Sample preparation}

All the chemicals were directly used without further purification. To start the procedure, $3.6 \mathrm{~mol}$ urea $\left(\mathrm{CO}\left(\mathrm{NH}_{2}\right)_{2}\right)$ was added to $5 \mathrm{M}$ zinc nitrate hexahydrate $\left(\mathrm{Zn}\left(\mathrm{NO}_{3}\right)_{2} \cdot 6 \mathrm{H}_{2} \mathrm{O}\right)$ solution under stirring at room temperature. The reaction was heated in an oil bath at $100-120{ }^{\circ} \mathrm{C}$ and stirred at $300 \mathrm{rpm}$ for $2 \mathrm{~h}$. After naturally cooling to room temperature, hot water was added to obtaining a white suspension. Subsequently, the precipitate was isolated by filtration and washed with water and ethanol several times to remove impurities. At the end, the white powder product was dried at $80^{\circ} \mathrm{C}$ for $24 \mathrm{~h}$. To study the effect of temperature on the microstructure and application performance, annealing treatment at different temperatures between $350{ }^{\circ} \mathrm{C}$ and $700{ }^{\circ} \mathrm{C}$ was realized. The thermal treatments were performed under air atmosphere. The heating ramp has a rise of $1{ }^{\circ} \mathrm{C} / \mathrm{min}$ and a cooling rate of $10^{\circ} \mathrm{C} / \mathrm{min}$ with a short dwelling time, $5 \mathrm{~min}$, to the desired temperature. The experimental details are schematically shown in Fig. S1 of the ESI.

\subsection{X-ray diffraction $(X R D)$}

Crystalline phases were characterized by X-ray diffraction (XRD, X'Pert PRO Theta/2theta of Panalytical, $\mathrm{Cu} \mathrm{K}_{\alpha}$ radiation, PANalytical, The Netherlands), using $\mathrm{CuK}_{\alpha}$ radiation. The patterns were recorded over the angular range $15-80^{\circ}(2 \theta)$ with a step size of $0.0334^{\circ}$ and a time per step of $100 \mathrm{~s}$, using $\mathrm{Cu} \mathrm{K}_{\alpha}$ radiation $(\lambda=0.154056 \mathrm{~nm})$ with working voltage and current of $40 \mathrm{kV}$ and $100 \mathrm{~mA}$, respectively. The lattice parameters were refined by a global simulation of the full diagram using the fullprof program employing crystalographic information obtained from the International Center for Diffraction Data (ICDD) PDF-2 database in the form of card 36-1451 for ZnO. The crystallite size is calculated from the full width at half-maximum of the diffraction peaks by using Scherrer's equation.

\subsection{Electron microscopy}

The morphology of the powders was evaluated using primary electron images of field emission scanning electron microscopy (FE-SEM, Hitachi S-4700). The composition of the powders was estimated using Energy Dispersive Spectroscopy, EDS. In the specific case of ZnO particles with fungi evaluation by SEM, the samples were prepared under the same conditions as antifungal activity tests, except for the change in the culture medium, using distilled water. After that, an aliquot is deposited in a sample holder for analysis. The average particle size was determined from FE-SEM micrographs by an image processing and analysis program (Leica Qwin, Leica Microsystems Ltd., Cambridge, England) considering > 200 particles in each measurement. To further understand the detailed morphology and crystal structure of the assynthesized $\mathrm{ZnO}$ nanostructures, a $400{ }^{\circ} \mathrm{C}$ sample was evaluated using a JEOL $2100 \mathrm{~F}$ transmission electron microscope (TEM/HRTEM) operating at $200 \mathrm{KV}$ and equipped with a field emission electron gun providing a point resolution of $0.19 \mathrm{~nm}$. For TEM sample preparation, the particles were carefully suspended in ethanol. The suspension was dropped on a copper TEM grid with carbon film support. The particles were kept at the grid after evaporation of ethanol.

\subsection{Textural characterization}

The specific surface area was determined by the BET method (SSA, Monosorb Surface Area Analyser MS-13, Quantachrome).

\subsection{Chemical analysis}

$\mathrm{Zn}^{2+}$ released was determined by inductively coupled plasma optical emission spectrometry (ICP-OES, Iris Advantage, Termo Jarrel Ash). For sample preparation, $10 \mathrm{~g} / \mathrm{L}$ of $\mathrm{ZnO}$ (as-prepared and references) was added in $25 \mathrm{~mL}$ of peptone water (PW). The suspension was centrifuged and decanted obtaining a colourless dissolution. Data are expressed in concentration in oxide form. 


\subsection{Antifungal activity tests}

As for antifungal activity, the pathogenic fungus Aspergillus niger (CECT 2807) was used for testing. Antifungal tests were performed by the Kirby-Bauer method (or agar diffusion method) with some modifications. First, the culture of $A$. niger (initial concentration of $5.20 \times 10^{7}$ spores $/ \mathrm{ml}$ ) was inoculated on the surface of Petri dishes. After, filter paper disks were impregnated with a suspension of different $\mathrm{ZnO}$ products with a concentration of $0.01 \%$ each one. The Petri dishes with the inoculums were then incubated at $37{ }^{\circ} \mathrm{C}$ for 3 days. The effectiveness of $\mathrm{ZnO}$ samples was evaluated by measuring the inhibition diameter of the grown fungus in the Petri dish and was compared with commercial references of $\mathrm{ZnO}$. All tests were performed in triplicate and the values were expressed in millimetres. Finally, two commercial references of $\mathrm{ZnO}$ were chosen based on their size, micro and nanosized. MicroZnO was purchased from Asturiana de Cinc and nanoZnO was purchased from Evonik. To compare the results between synthesized samples and the reference materials, both commercial ZnOs were thermally treated at $500{ }^{\circ} \mathrm{C}$. The morphology of the MicroZnO materials shows a typical $\mathrm{ZnO}$ morphology, consisting mainly of elongated prismatic particles and nearly hexagonal particles, with sizes of $0.2-1.0$ $\mu \mathrm{m}$ and an average particle size $0.5 \mu \mathrm{m}$, see ESI Fig. S2a. Meanwhile, the nanoZnO is characterized by small spherical particles of $15-30 \mathrm{~nm}$, which form globular agglomerates, see Figs. S2(b-c) of the ESI.

\section{Results and discussion}

\subsection{Design and characterization of hierarchical structure}

After annealing treatment of $\mathrm{ZnO}$ "hierarchical structure", hereinafter $\mathrm{ZnO}$ hierarchical particles, a basic identification of the structure was performed using X-Ray Diffraction, XRD, (see Fig. S3 in the ESI). The position and intensity of diffraction peaks match to hexagonal wurtzite structure ZnO (JCPDS Card No. 36-1451), Fig. S3a (ESI). No other peaks are detected, which means no residual reactants or intermediates are present. No significant changes are detected in the XRD pattern after such thermal treatment. From the Fig. S3b (ESI), we can observe that the $\mathrm{ZnO}$ crystallite size grows moderately as temperature increases. In the case of lattice parameters, both $a$ and $c$, remains practically constant throughout the temperature range between $350{ }^{\circ} \mathrm{C}$ and $700{ }^{\circ} \mathrm{C}$.
Moreover, their values are in good agreement with the space group $\mathrm{P}_{3}$ mc confirming the $\mathrm{ZnO}$ hexagonal structure. Summarizing, these results indicate the successful synthesis of crystallized $\mathrm{ZnO}$ by soft chemistry without any secondary products.

The XRD technique gives structural information of the $\mathrm{ZnO}$ but yields no morphological information. In order to determine the morphology of the $\mathrm{ZnO}$ hierarchical particles, field emission scanning electron microscopy (FE-SEM) is made, Fig. 1. At lower magnifications (first row, Fig. 1a-e), we can see well dispersed agglomerates. These agglomerates have a spherical shape and a diameter about ca. $5 \mu \mathrm{m}$. From the high resolution scanning electron microscope (HR-SEM) images (second row of the Fig. $1 \mathrm{f}-\mathrm{j}$ ), we can see that the $\mathrm{ZnO}$ agglomerates consist of welldefined flower shaped particles with equivalent diameters of $\sim 3 \mu \mathrm{m}$, which remains almost constant on the selected temperature range. Each flower is formed by a combination of 5 or more petals plus a centre that can be called "pistil". A keen observation at higher magnifications (third row, Fig. 1k-0) shows in detail the centre of the flower. Pistil is composed of hexagonal platelets of $500 \mathrm{~nm}$, approximately, typical of the wurtzite structure; see Figs. 1k-o. Moreover, some isolated nanoparticles around these hierarchical organizations can also be observed in Fig. 1, especially at low thermal treatments (see Figs. $1 \mathrm{k}$ and $\mathrm{l}$ ). In the temperature range between $350{ }^{\circ} \mathrm{C}$ and $500^{\circ} \mathrm{C}$, these nanoparticles increase in size with the temperature, 30,50 and $100 \mathrm{~nm}$ respectively (Fig. S4). As the temperature increases to $600{ }^{\circ} \mathrm{C}$ and $700{ }^{\circ} \mathrm{C}$, the presence of nanoparticles is not observed. Therefore, the thermal treatment provokes the nanoparticles coalesce to build larger nanoparticles, which end up forming part of the flower-like structure. These facts allow us to build a mechanistic pathway for the formation of flower-like $\mathrm{ZnO}$ nanostructured.

\subsection{How is it possible to form hierarchical micrometric flowers?}

To further understand the detailed morphology and crystal structure of the $\mathrm{ZnO}$ hierarchical particles, a $400{ }^{\circ} \mathrm{C}$ sample was analysed by transmission electron microscope (TEM/HRTEM, 2100F, Jeol). Fig. 2a shows a TEM image of isolated flower shaped $\mathrm{ZnO}$, selecting one of the multiple petals for its study. At high-magnification TEM images of an individual petal (see Fig. 2b-c), and a nanoparticle can be clearly found. Increasing magnifications, Fig. 2d displays a nanoparticle deposited on petal with very well-faceted crystals. In petals, their side faces have exposed
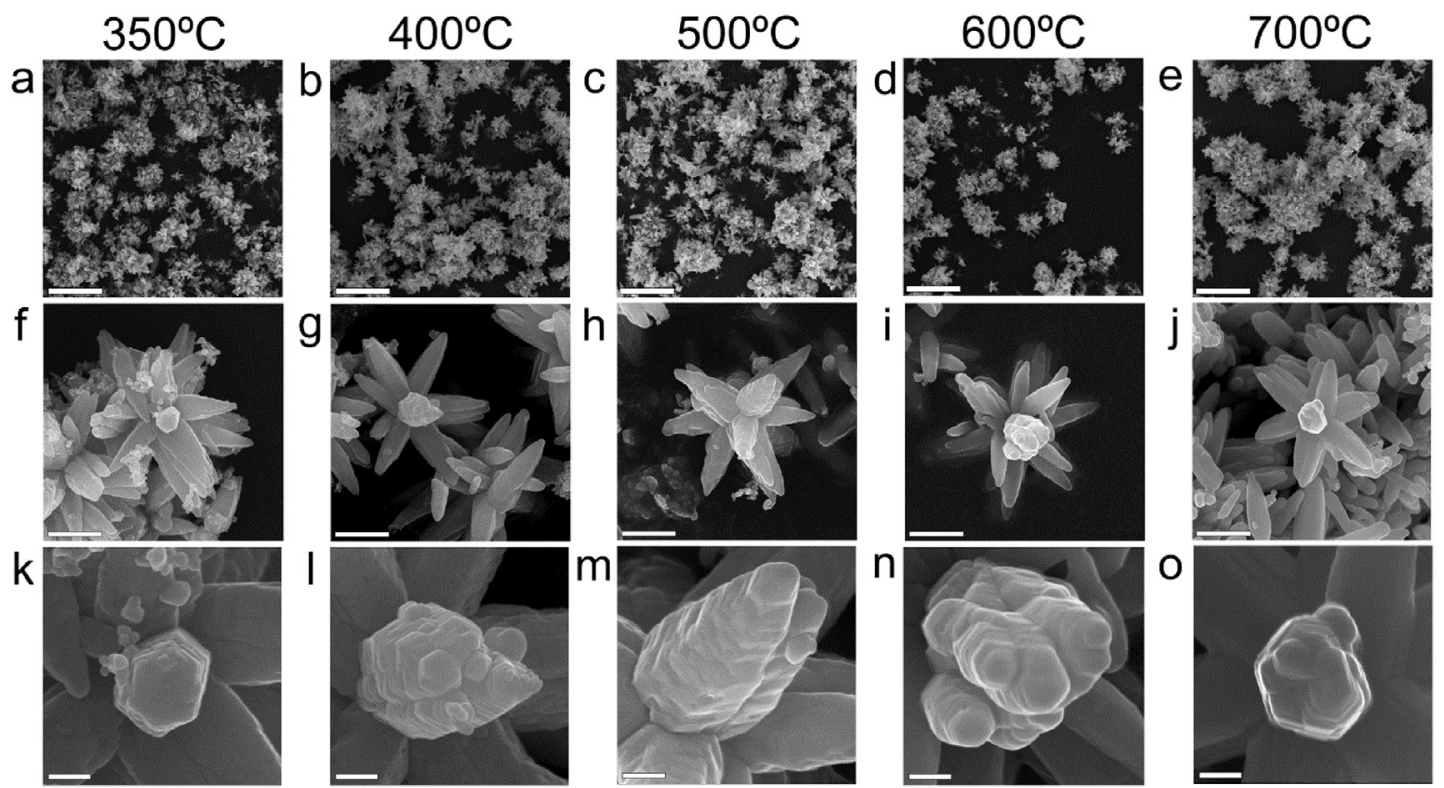

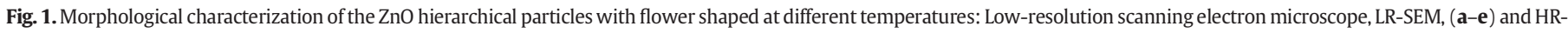

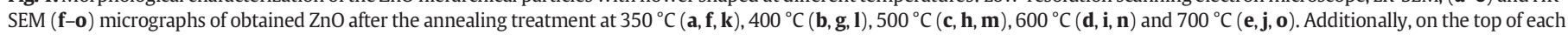
image, the annealing temperature value is indicated. Scale bar of the panels a-e is $10 \mu \mathrm{m}$, panels $\mathrm{f}-\mathrm{j}$ is $1 \mu \mathrm{m}$ and $\mathrm{k}-\mathrm{o}$ is $200 \mathrm{~nm}$. 




b

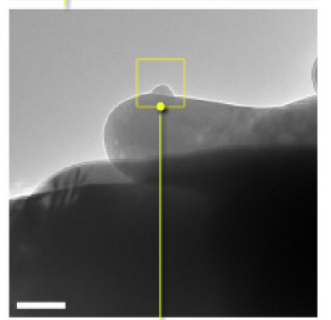

C

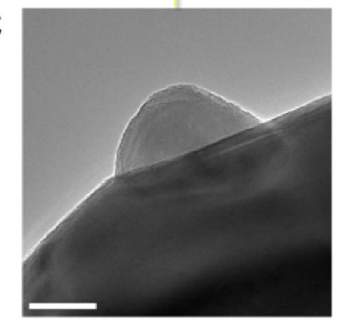

e

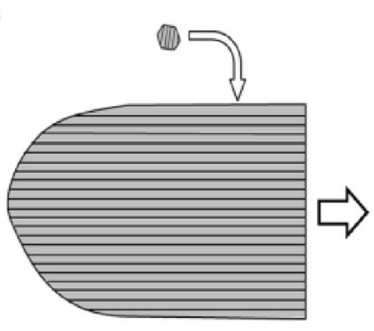

d
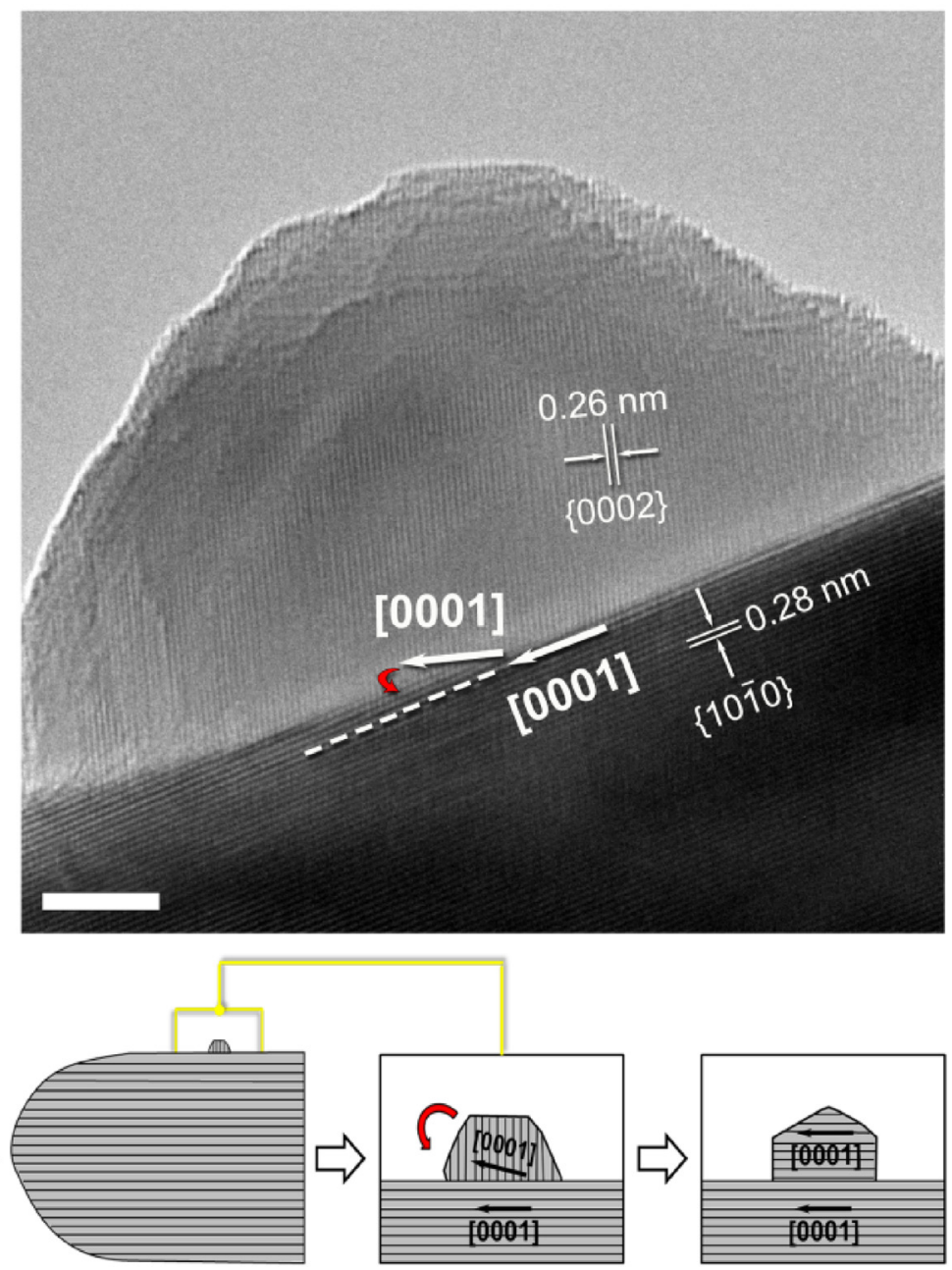

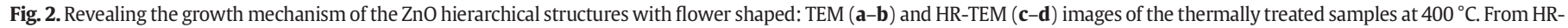

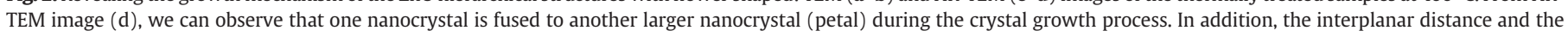

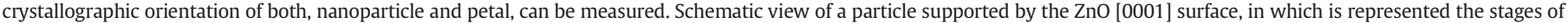
the growth mechanism based on orientation attachment. Scale bar of the panel a is $1 \mu \mathrm{m}$, panel b is $100 \mathrm{~nm}$, panel c is $20 \mathrm{~nm}$ and panel $\mathrm{d}$ is $5 \mathrm{~nm}$.

$\{1010\}$ facets and are very flat, in good agreement with previous works $[31,32]$, confirming that they are single crystalline and elongated along the [0001] axis. While on the nanoparticle, measured lattice spacing of adjacent lattice planes is about $0.26 \mathrm{~nm}$, corresponding to the $\{0002\}$ plane of wurtzite hexagonal $\mathrm{ZnO}$, indicating different crystallographic orientation between nanoparticle and petal. Fig. 2(d) further demonstrates oriented aggregation and a coarsening process whereby one nanocrystal is fused to another larger nanocrystal, in this case the petal, during the crystal growth process. The isolated nanoparticle collides and coalesces in the same crystallographic orientation that it

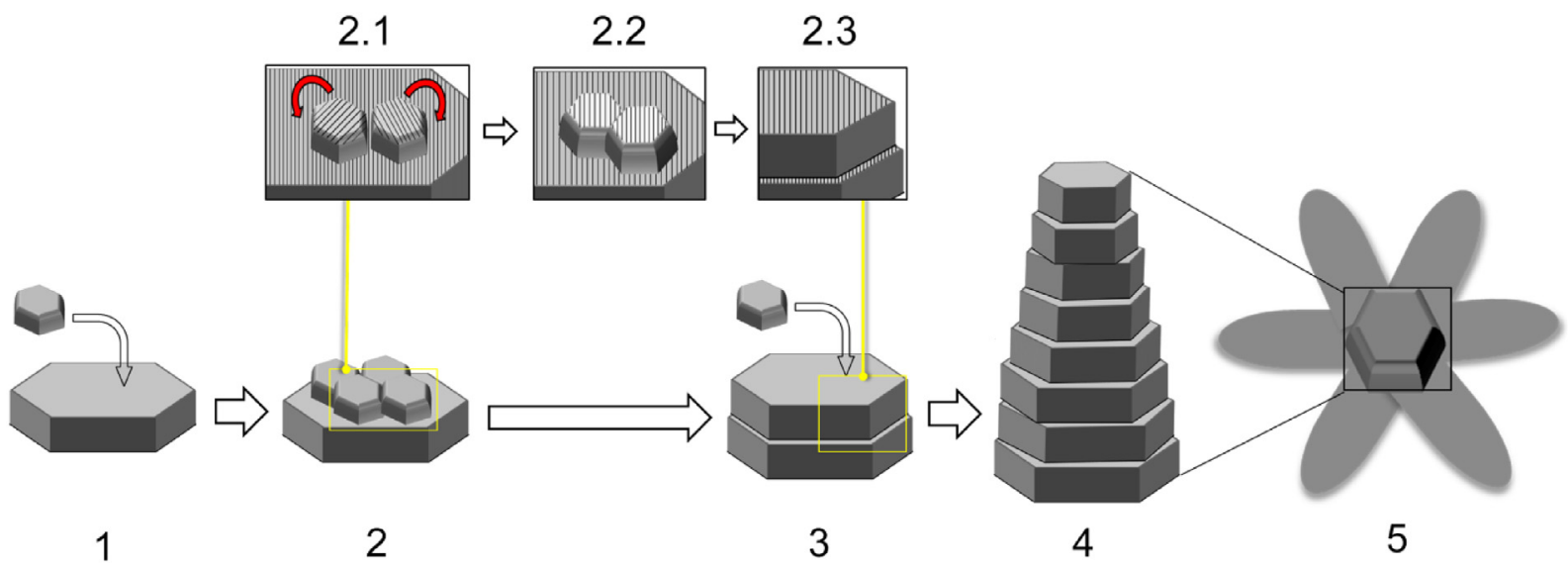

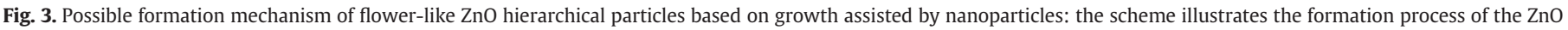


formed stage. (A detailed explanation of the scheme can be followed by the text of the main body). 
possesses the larger nanocrystal, [0001], which is the most thermodynamically stable direction on $\mathrm{ZnO}$ structure. This behaviour is favoured by the thermal treatment, which is in agreement with the results obtained in Fig. 1n-o for annealing temperatures between 600 and $700{ }^{\circ} \mathrm{C}$. Based on the above results, we pose a simple model of hierarchical structures growth with flower shaped by orientation attachment (OA) $[33,34]$ of nanoparticles and petals, where petals play as an orientation template (Fig. 2e). Thanks to this mechanism is possible to demonstrate oriented aggregation and a growth process whereby nanoparticles irreversibly attach to "template" in slightly oriented fashion to produce the petals.

From the perspective of the microstructure and keeping in mind the stages of posed growth in the Fig. 2, the experimental results observed here can be interpreted as follows. Firstly, a group of nanoparticles are sintered to form a nanoplatelet (see stage marked as $\mathbf{1}$ in Fig. 3). Through the diffusion mechanism, a new group of nanoparticles is deposited on the platelet to build another hexagonal layer (stage 2 of the Fig. 3). This behaviour can be seen at low temperatures micrographs (Fig. 1k and 1), where nanoparticles are hierarchical organized. The stages marked as $\mathbf{2 . 1 - 2 . 3}$ on the Fig. 3 show, in detail, the formation of nanoplatelet by orientated attachment (OA). Nanoparticles are disoriented among them, so they rotate to match each other, (stage 2.1). An increase in the annealing temperature provokes that the agglomerates of the nanoparticles consolidate and coalesce (stage 2.2), leading to the formation oriented of larger nanoplatelets with the same crystallographic orientation of [0001]; stage represented by the points $\mathbf{2 . 3}$ and $\mathbf{3}$ in the Fig. 3. This crystallographic orientation, [0001], must be the same as formed nanoplatelet for correct aggregation, which is the most thermodynamically stable direction in $\mathrm{ZnO}$. The growth continues with annealing treatments allowing the formation of new sheets becoming smaller (stage 4). Finally, this platelet stacking is part of the flower-shaped structure (stage 5). Since each platelets stack can be oriented differently from a common origin, i.e., vertical stacks build the pistil and horizontal stacks represent the petals. We can call this mechanistic pathway as epitaxial growth mediated by nanoparticles due to similarity with this stepwise growth and the main role of nanoparticles during the process. However, platelet distribution is not aligned growing, each level is randomly rotated to its predecessor as Fig. 1k-o displays at high magnifications getting screwedlike petals. Some authors attribute this screw character to spiral growth, which occurs during orientated attachment $[35,36]$.

\subsection{To obtain fungicidal activity, avoiding the potential toxicity of the nanoparticles}

Keeping in mind the potential toxicity that implies the NPs utilization; an important aspect to consider, related to size, is the specific surface area (SSA). So, we calculated the minimum theoretical SSA of different nanoparticles morphologies (detailed explanation of calculation in ESI). Selected nanostructures are sphere, fibre and plate (see Fig. S5). The calculations allow dividing into two behaviours the specific surface area: Microscale and Nanoscale, depending on position above or below with respect to theoretical structures (see Fig. 4a). Then, specific surface area of samples is classified in these ranges. SSA of ZnO hierarchical particles is calculated by Brunauer-Emmett-Teller (BET) method. For comparison, two different sized commercial products are used in this study: microZnO and nanoZnO references. These data are represented in Fig. 4a. As expected, SSA nanoZnO $\left(23.9 \mathrm{~m}^{2} / \mathrm{g}\right)$ reference is located in the nanoscale behaviour. SSA of microZnO reference $\left(4.6 \mathrm{~m}^{2} / \mathrm{g}\right)$ is placed close to microscale behaviour. To our surprise, SSAs of ZnO hierarchical particles (from 1.8 to $1 \mathrm{~m}^{2} / \mathrm{g}$ ) are even lower than commercial microZnO. These samples are sited in microscale behaviour. In addition, the SSA evolution with the annealing treatment (blue arrow of Fig.4a) reveals that at higher thermally treatment, specific surface area decreases. Thus, the results suggest that the platelets can be very compacted with each other, blocking some pores which are created on the synthesis. Hence, annealing temperature play an important role in the compaction process of platelets, which allows tune SSA in samples. Another factor that may indicate the potential toxicity of $\mathrm{ZnO}$ is the $\mathrm{Zn}^{2+}$ cation released, so a chemical analysis of $\mathrm{ZnO}$ in solution was performed. Fig. $4 \mathrm{~b}$ shows concentration of $\mathrm{Zn}^{2+}$ cation in dissolution for synthesized $\mathrm{ZnO}$ and references. NanoZnO presents the highest value $\left(8 \mathrm{mg} \mathrm{L}^{-1}\right)$. Conversely, microZnO $\left(0.7 \mathrm{mg} \mathrm{L}^{-1}\right)$ and as-prepared $\mathrm{ZnO}$ $\left(<1 \mathrm{mg} \mathrm{L}^{-1}\right.$ ) have lower values than nanoZnO. A keen observation of flower-like $\mathrm{ZnO}$ annealed shows a $\mathrm{Zn}^{2+}$ released concentration with values close to the microZnO reference (see Fig. 4c). All these data are indicative that the nanostructured $\mathrm{ZnO}$ is potentially safer than the nanoparticles, regarding these parameters analysed.

In order to understand the behaviour of flower-like $\mathrm{ZnO}$ against fungus growth, Kirby-Bauer method is used. A. niger is cultivated on petri dishes containing $\mathrm{ZnO}$ hierarchical particles thermally treated and incubated at $37{ }^{\circ} \mathrm{C}$ for 3 days. As shown in Fig. $4 \mathrm{~d}, \mathrm{ZnO}$ affects the development of fungus. To better know how much more effective is prepared $\mathrm{ZnO}$, different sized commercial references are used again. Fig. $4 \mathrm{e}$ shows the reduction of fungal growth for $\mathrm{ZnO}$ hierarchical particles, microZnO reference and nanoZnO reference. The averages of sporulation inhibition diameters are $24 \mathrm{~mm}, 27 \mathrm{~mm}$ and $34 \mathrm{~mm}$ for micro, nano and synthesized $\mathrm{ZnO}$ respectively (see ESI Fig. S6). The above results indicate that flower-like $\mathrm{ZnO}$ nanostructured increases the antifungal activity about $42 \%$ respect to microZnO and $26 \%$ to nanoZnO. For this reason, the $\mathrm{ZnO}$ hierarchical particles significantly inhibit the growth of $A$. niger being more effective than $\mathrm{ZnO}$ commercial products.

\subsection{Looking for the main factors of antifungal activity}

The detailed mechanism for the antifungal activity of $\mathrm{ZnO}$ is still under debate. However, previous studies show several factors that can affect the antimicrobial activity [37-39]. These factors can be divided into physical, chemical and a combination of them, shown schematically in Fig. S7. The most important physical interactions are electrostatic effect, abrasion of membrane envelope and penetration of particles through the cell. As to chemical interactions, there are two possibilities: reactive oxygen species (ROS) production and $\mathrm{Zn}^{2+}$ release. This led us to investigate what factors delimit antifungal activity of ZnO hierarchical particles. Some authors report the higher resistance of fungi to $\mathrm{ZnO}$ that may come from their less sensitivity to ROS [40,41]. However, the presence of $\mathrm{Zn}^{+2}$ cations can alter the respiratory chain of cells, causing their death [42]. A chemical analysis also serves to check the antifungal importance of $\mathrm{Zn}^{2+}$ released (Fig. $4 \mathrm{~b}$ ). The highest value of nanoZnO suggests a strong participation of $\mathrm{Zn}^{2+}$ in antifungal activity, and therefore, in this case the chemical interactions govern the antifungal activity. On the other hand, the low values of microZnO and as-prepared $\mathrm{ZnO}$ pose other action mechanisms like physical interactions. Nanostructured $\mathrm{ZnO}$ annealed below $500^{\circ} \mathrm{C}$ displays a $\mathrm{Zn}^{2+}$ release slightly higher than the microZnO reference. Accordingly, at $350-400{ }^{\circ} \mathrm{C}$ there may be a very small contribution of these cations to the antifungal mechanism, as in the case of nanoznO. Broadly, these results discarded chemical interactions like principal mechanism of flower-like $\mathrm{ZnO}$. To know if physical interactions are present in the antifungal mechanism of ZnO hierarchical particles, a FE-SEM study is performed. The contact between spores and flower-like $\mathrm{ZnO}$ is observed in Fig. 5. As shown, the $\mathrm{ZnO}$ hierarchical particles favour the cracking (Fig. 5a), punctures (Fig. 5b) and rupture of the spore membrane (Fig. $5 \mathrm{c}$ ). A possible explanation of this effect is the abrasive surface texture of $\mathrm{ZnO}$ caused by the uneven surface texture due to rough edges and corners [25]. These properties fit with the morphology of flower-like $\mathrm{ZnO}$, giving rough surfaces which contributes to the mechanical damage of the membrane. To ensure correct allocation of spores, an EDS study is performed. The EDS mappings, represented in Fig. 5d-e, display the main atom of each structure, i.e. carbon for spores and zinc for flower-like $\mathrm{ZnO}$. Turning to other physical factors, penetration of particles through the cell is not possible due to large size differences between synthesized $\mathrm{ZnO}$ and the pores of the membrane, as shown in Fig. 5. 

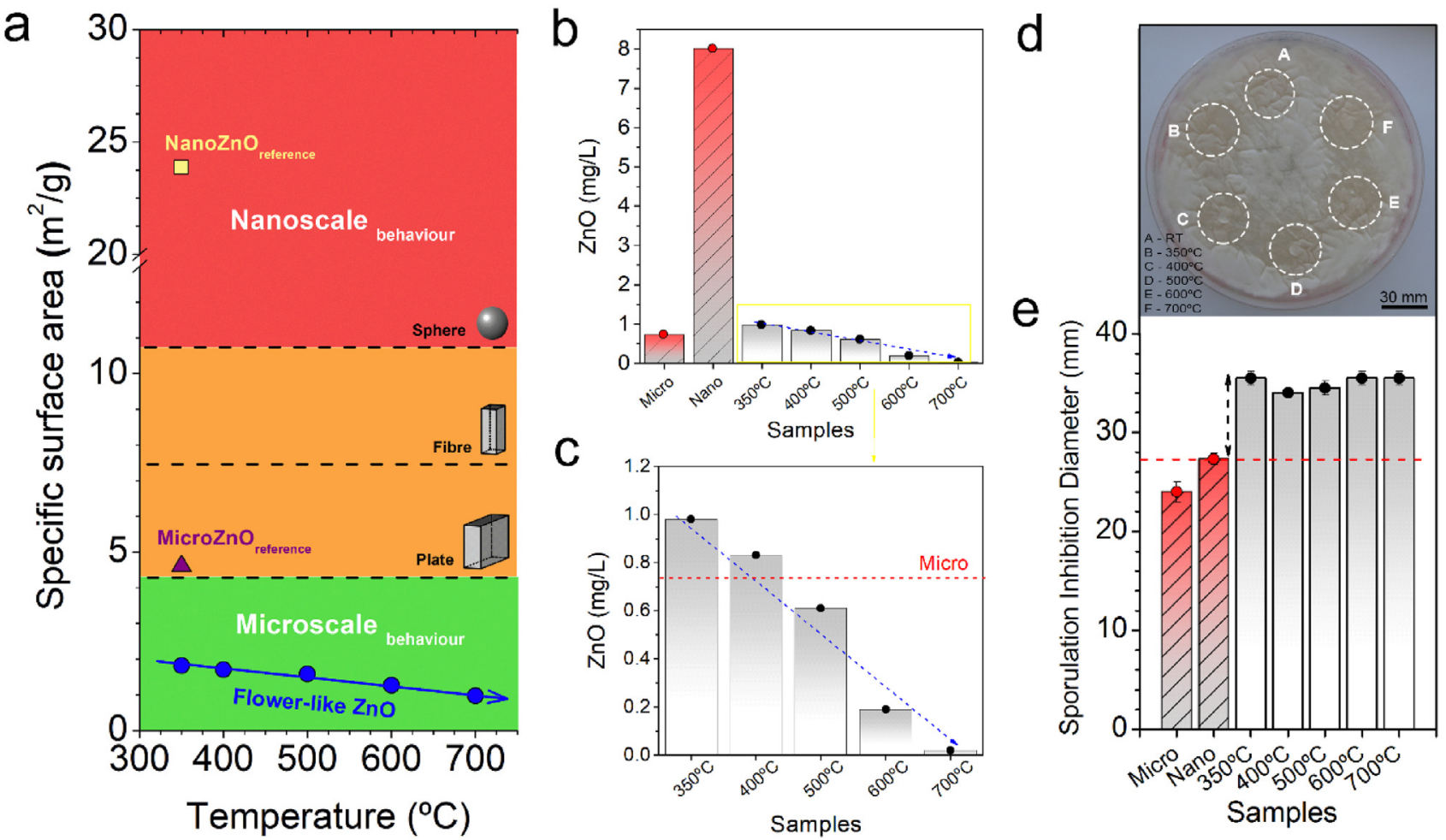

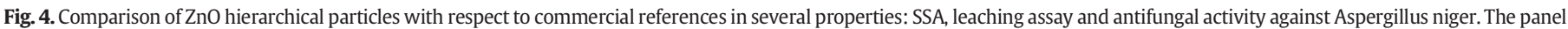



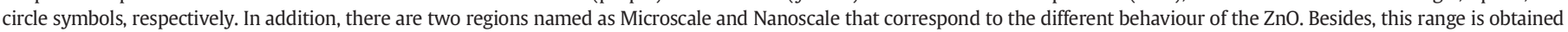

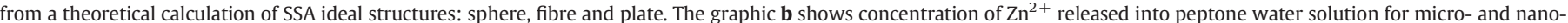

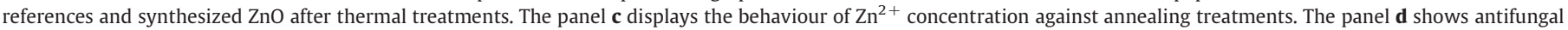

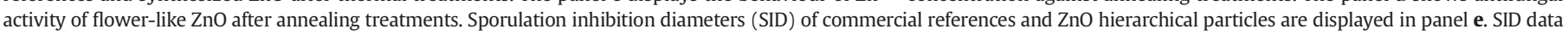


the reader is referred to the web version of this article.)

Therefore, after these results an action mechanism of flower-like $\mathrm{ZnO}$ against fungi is outlined. The $\mathrm{ZnO}$ hierarchical particle mechanism is fundamentally based on physical interactions. As shown in Fig. 6, the procedure can be divided into four stages. At first stage (Fig. 6.1), the $\mathrm{ZnO}$ hierarchical particles are approaching the spore until contact between them is reached. This is achieved because of the affinity between the two species, $\mathrm{ZnO}$ and fungi. Second step (Fig. 6.2) displays the first consequences of $\mathrm{ZnO}$ hierarchical particle abrasion. The flower-like $\mathrm{ZnO}$ punctures the spore and causes cracking in the fungus membrane. After that, membrane damage like cracking, wrinkling, rupture, etc. causes leakage of intramembrane components (Fig. 6.3). In the last stage (Fig. 6.4), the spore ends "holey" by the abrasive action of $\mathrm{ZnO}$ hierarchical particles. All these membrane damage finally causes the fungi death. Moreover, ZnO hierarchical particles saves the flower-like
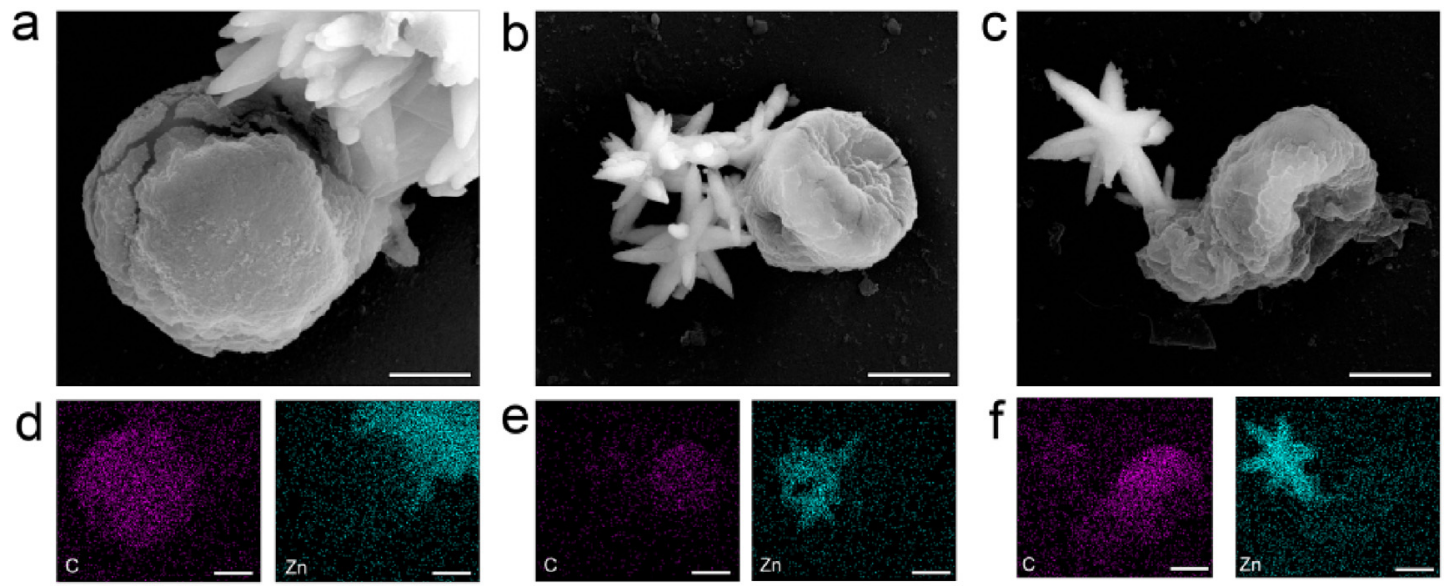



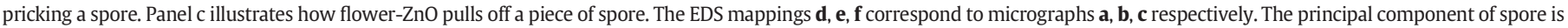

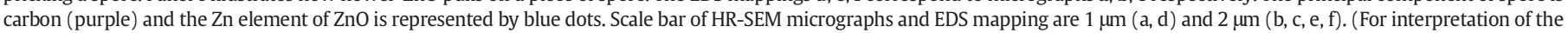
references to colour in this figure legend, the reader is referred to the web version of this article.) 


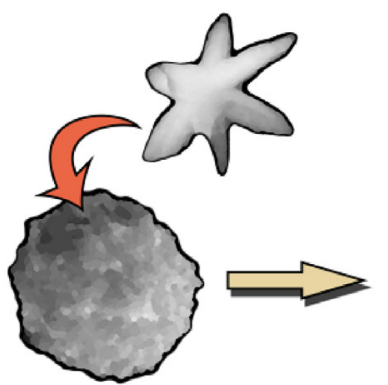

1

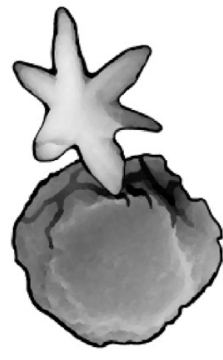

2
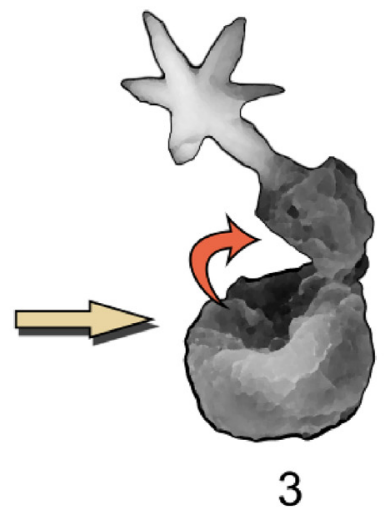

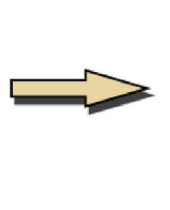

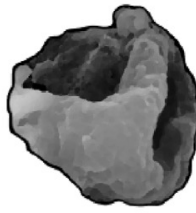

4

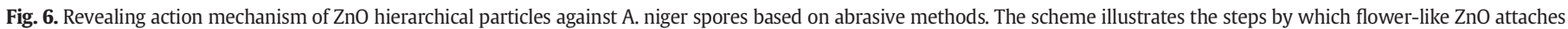
spores; (1) contact between $\mathrm{ZnO}$ and spore, (2) cracking and pricking spore, (3) total or partial rupture of the spore and (4) spore "holey" that prevents the growth of fungus.

structure throughout the mechanism (Fig. 5a-c) keeping the micrometric behaviour. Hence, the hierarchical structure is available for new abrasion attacks, allowing a long-lasting antifungal activity.

\section{Conclusions}

In summary, we have synthesized flower-like $\mathrm{ZnO}$ nanostructured by soft chemistry providing an easy route and cost-effective process. The present study reveals a possible formation mechanism of flower shaped $\mathrm{ZnO}$ by nanoparticles diffusion with orientation attachment. The obtained $\mathrm{ZnO}$ hierarchical particles after annealing treatments show a SSA of micrometric behaviour. The low $\mathrm{Zn}^{2+}$ release in solution, is also another indicative of a very different behaviour than the nanoparticles. Furthermore, $\mathrm{ZnO}$ hierarchical particles enhance antifungal activity against $A$. niger respect to commercial references using mainly physical mechanisms as abrasion. Therefore, $\mathrm{ZnO}$ hierarchical particles generate a new concept of materials with a combination of micro and nanoparticles properties, reducing the potential negative effects of nanoparticles.

\section{Competing financial interests}

The authors declare no competing financial interests.

\section{Acknowledgements}

This work was supported by the Spanish Ministry of Economy and Competitiveness (MINECO) under projects MAT2013-48009-C4-1-P. The Spanish National Research Council (CSIC) under project NANOMIND CSIC 201560E068. Dr. F. Rubio-Marcos is also indebted to MINECO for a "Juan de la Cierva" contract (ref: JCI-2012-14521), which is co-financed with FEDER funds F. R-M is also indebted to MINECO for a 'Ramon y Cajal' contract (ref: RyC-2015-18626), which is co-financed by the European Social Fund. Finally, the authors are grateful to Mercedes Monte-Serrano, Santiago De-Bernardi and Javier Menéndez for antimicrobial activity test.

\section{Appendix A. Supplementary data}

Supplementary data to this article can be found online at http://dx. doi.org/10.1016/j.matdes.2017.08.038.

\section{References}

[1] K. Foe, G. Namkoong, T.M. Abdel-Fattah, H. Baumgart, M.S. Jeong, D.-S. Lee, Controlled synthesis of $\mathrm{ZnO}$ spheres using structure directing agents, Thin Solid Films 534 (2013) 76-82, http://dx.doi.org/10.1016/j.tsf.2013.01.105.

[2] K. He, G. Zhao, G. Han, Facile synthesis of novel hierarchical hollow ZnO microspheres, CrystEngComm 16 (2014) 3853, http://dx.doi.org/10.1039/c3ce42563k.
[3] Ü. Özgür, Y.I. Alivov, C. Liu, A. Teke, M.A. Reshchikov, S. Doğan, V. Avrutin, S.-J. Cho, $\mathrm{H}$. Morko, A comprehensive review of ZnO materials and devices, J. Appl. Phys. 98 (2005) 1-103, http://dx.doi.org/10.1063/1.1992666.

[4] Z.L. Wang, Nanostructures of zinc oxide, Mater. Today 7 (2004) 26-33, http://dx.doi. org/10.1016/S1369-7021(04)00286-X.

[5] L. Schlur, A. Carton, G. Pourroy, A new zinc hydroxy acetate hydrogen carbonate lamellar phase for growing large and clean $\mathrm{ZnO}$ nanorod arrays, Chem. Commun. 51 (2015) 3367-3370, http://dx.doi.org/10.1039/c4cc09982f.

[6] A. Quintana, A. Gómez, M.D. Baró, S. Suriñach, E. Pellicer, J. Sort, Self-templating faceted and spongy single-crystal $\mathrm{ZnO}$ nanorods: resistive switching and enhanced piezoresponse, Mater. Des. 133 (2017) 54-61, http://dx.doi.org/10.1016/j.matdes. 2017.07.039.

[7] B. Won, I. Park, G. Yi, M. Kim, S.J. Pennycook, ZnO nanoneedles grown vertically on Si substrates by non-catalytic vapor-phase epitaxy, Adv. Mater. 14 (2002) 1841-1843, http://dx.doi.org/10.1002/adma.200290015.

[8] P. Yang, H. Yan, S. Mao, R. Russo, J. Johnson, R. Saykally, N. Morris, J. Pham, R. He, H.-J. Choi, Controlled growth of $\mathrm{ZnO}$ nanowires and their optical properties, Adv. Funct. Mater. 12 (2002) 323-331, http://dx.doi.org/10.1002/1616-3028(20020517)12: 5<323::AID-ADFM323>3.0.CO;2-G.

[9] Z.W. Pan, Nanobelts of semiconducting oxides, Science 80 (291) (2001) 1947-1949, http://dx.doi.org/10.1126/science.1058120.

[10] A. Pan, R. Yu, S. Xie, Z. Zhang, C. Jin, B. Zou, ZnO flowers made up of thin nanosheets and their optical properties, J. Cryst. Growth 282 (2005) 165-172, http://dx.doi.org/ 10.1016/j.jcrysgro.2005.05.003.

[11] W.S. Chiu, P.S. Khiew, M. Cloke, D. Isa, T.K. Tan, S. Radiman, R. Abd-Shukor, M.A.A. Hamid, N.M. Huang, H.N. Lim, Photocatalytic study of two-dimensional ZnO nanopellets in the decomposition of methylene blue, Chem. Eng. J. 158 (2010) 345-352, http://dx.doi.org/10.1016/j.cej.2010.01.052.

[12] L. Lin, X. Peng, S. Chen, B. Zhang, Y. Feng, Preparation of diverse flower-like ZnO nanoaggregates for dye-sensitized solar cells, RSC Adv. 5 (2015) 25215-25221, http://dx.doi.org/10.1039/C5RA01938A.

[13] C. Li, G. Li, C. Shen, C. Hui, J. Tian, S. Du, Z. Zhang, H.-J. Gao, Atomic-scale tuning of self-assembled ZnO microscopic patterns: from dendritic fractals to compact island, Nano 2 (2010) 2557-2560, http://dx.doi.org/10.1039/c0nr00421a.

[14] P.X. Gao, Z.L. Wang, Mesoporous polyhedral cages and shells formed by textured self-assembly of ZnO nanocrystals, J. Am. Chem. Soc. 125 (2003) 11299-11305, http://dx.doi.org/10.1021/ja035569p.

[15] L. Schmidt-Mende, J.L. MacManus-Driscoll, ZnO - nanostructures, defects, and devices, Mater. Today 10 (2007) 40-48, http://dx.doi.org/10.1016/S13697021(07)70078-0.

[16] A. Kołodziejczak-Radzimska, T. Jesionowski, Zinc oxide-from synthesis to application: a review, Materials (Basel) 7 (2014) 2833-2881, http://dx.doi.org/10.3390/ ma7042833.

[17] C. Tian, Q. Zhang, A. Wu, M. Jiang, Z. Liang, B. Jiang, H. Fu, Cost-effective large-scale synthesis of $\mathrm{ZnO}$ photocatalyst with excellent performance for dye photodegradation, Chem. Commun. 48 (2012) 2858, http://dx.doi.org/10.1039/c2cc16434e.

[18] G. Byzynski, C. Melo, D.P. Volanti, M.M. Ferrer, A.F. Gouveia, C. Ribeiro, J. Andrés, E. Longo, The interplay between morphology and photocatalytic activity in $\mathrm{ZnO}$ and N-doped ZnO crystals, Mater. Des. 120 (2017) 363-375, http://dx.doi.org/10.1016/ j.matdes.2017.02.020.

[19] J. Wang, J. Yang, N. Han, X. Zhou, S. Gong, J. Yang, P. Hu, Y. Chen, Highly sensitive and selective ethanol and acetone gas sensors based on modified $\mathrm{ZnO}$ nanomaterials, Mater. Des. 121 (2017) 69-76, http://dx.doi.org/10.1016/j.matdes.2017.02.048.

[20] E. de Lucas-Gil, F. Rubio-Marcos, P. Leret, B. Motos-Pérez, M. Monte-Serrano, J. Menéndez, J.F. Fernández, Opening a new gate to glass preservative with long-lasting antimicrobial activity as replacement of parabens, ACS Sustain. Chem. Eng. 5 (2017) 294-302, http://dx.doi.org/10.1021/acssuschemeng.6b01609.

[21] L.C. Ann, S. Mahmud, A. Seeni, S.K.M. Bakhori, A. Sirelkhatim, D. Mohamad, H. Hasan, Structural morphology and in vitro toxicity studies of nano- and micro-sized zinc oxide structures, J. Environ. Chem. Eng. 3 (2015) 436-444, http://dx.doi.org/10. 1016/j.jece.2014.12.015.

[22] A. Sirelkhatim, S. Mahmud, A. Seeni, N.H.M. Kaus, L.C. Ann, S.K.M. Bakhori, H. Hasan, D. Mohamad, Review on zinc oxide nanoparticles: antibacterial activity and toxicity 
mechanism, Nano-Micro Lett. 7 (2015) 219-242, http://dx.doi.org/10.1007/s40820015-0040-X.

[23] R. Kumar, A. Umar, G. Kumar, H.S. Nalwa, Antimicrobial properties of ZnO nanomaterials: a review, Ceram. Int. (2016) http://dx.doi.org/10.1016/j.ceramint. 2016.12.062.

[24] O. Yamamoto, Influence of particle size on the antibacterial activity of zinc oxide, Int J. Inorg. Mater. 3 (2001) 643-646, http://dx.doi.org/10.1016/S14666049(01)00197-0.

[25] N. Padmavathy, R. Vijayaraghavan, Enhanced bioactivity of ZnO nanoparticles-an antimicrobial study, Sci. Technol. Adv. Mater. 9 (2008) 35004, http://dx.doi.org/10. 1088/1468-6996/9/3/035004.

[26] G. Applerot, A. Lipovsky, R. Dror, N. Perkas, Y. Nitzan, R. Lubart, A. Gedanken, Enhanced antibacterial activity of nanocrystalline $\mathrm{ZnO}$ due to increased ROSmediated cell injury, Adv. Funct. Mater. 19 (2009) 842-852, http://dx.doi.org/10. 1002/adfm.200801081.

[27] A. Lipovsky, Y. Nitzan, A. Gedanken, R. Lubart, Antifungal activity of ZnO nanoparticles-the role of ROS mediated cell injury, Nanotechnology 22 (1051011-5) (2011) http://dx.doi.org/10.1088/0957-4484/22/10/105101.

[28] L. He, Y. Liu, A. Mustapha, M. Lin, Antifungal activity of zinc oxide nanoparticles against Botrytis cinerea and Penicillium expansum, Microbiol. Res. 166 (2011) 207-215, http://dx.doi.org/10.1016/j.micres.2010.03.003.

[29] J. Heim, E. Felder, M.N. Tahir, A. Kaltbeitzel, U.R. Heinrich, C. Brochhausen, V. Mailänder, W. Tremel, J. Brieger, Genotoxic effects of zinc oxide nanoparticles, Nano 7 (2015) 8931-8938, http://dx.doi.org/10.1039/C5NR01167A.

[30] T.V. Duncan, The communication challenges presented by nanofoods, Nat Nanotechnol. 6 (2011) 683-688, http://dx.doi.org/10.1038/nnano.2011.193.

[31] B. Liu, H.C. Zeng, Hydrothermal synthesis of $\mathrm{ZnO}$ nanorods in the diameter regime of 50 nm, J. Am. Chem. Soc. 125 (2003) 4430-4431, http://dx.doi.org/10.1021/ ja0299452.

[32] G. Tang, Y. Wen, A. Pang, D. Zeng, Y. Zhang, S. Tian, B. Shan, C. Xie, The atomic origin of high catalytic activity of $\mathrm{ZnO}$ nanotetrapods for decomposition of ammonium perchlorate, CrstEngComm (2014) http://dx.doi.org/10.1039/c3ce41435c.

[33] J. Zhang, F. Huang, Z. Lin, Progress of nanocrystalline growth kinetics based on oriented attachment, Nano 2 (2010) 18-34, http://dx.doi.org/10.1039/b9nr00047j.
[34] J.M. Wu, Y. Chen, W.T. Kao, Ultrafine ZnO nanoparticles/nanowires synthesized on a flexible and transparent substrate: formation, water molecules, and surface defect effects, ACS Appl. Mater. Interfaces 6 (2014) 487-494, http://dx.doi.org/10.1021/ am404532q.

[35] R.L. Penn, Imperfect oriented attachment: dislocation generation in defect-free nanocrystals, Science 281 (80) (1998) 969-971, http://dx.doi.org/10.1126/science. 281.5379.969.

[36] F. Wang, X. Wang, Mechanisms in the solution growth of free-standing twodimensional inorganic nanomaterials, Nano 6 (2014) 6398-6414, http://dx.doi. org/10.1039/c4nr00973h.

[37] L. Zhang, Y. Jiang, Y. Ding, N. Daskalakis, L. Jeuken, M. Povey, A.J. O'Neill, D.W. York, Mechanistic investigation into antibacterial behaviour of suspensions of $\mathrm{ZnO}$ nanoparticles against E. coli, J. Nanoparticle Res. 12 (2010) 1625-1636, http://dx.doi.org/ 10.1007/s11051-009-9711-1.

[38] L.-E. Shi, Z-H. Li, W. Zheng Y.-F. Zhao, Y.-F. Jin, Z-X. Tang Synthesis, antibacterial activity, antibacterial mechanism and food applications of $\mathrm{ZnO}$ nanoparticles: a review, Food Addit. Contam. Part A Chem. Anal. Control Expo. Risk Assess. 31 (2014) 173-186, http://dx.doi.org/10.1080/19440049.2013.865147.

[39] Y. Jiang, L. Zhang, D. Wen, Y. Ding, Role of physical and chemical interactions in the antibacterial behavior of ZnO nanoparticles against E. coli, Mater. Sci. Eng. C 69 (2016) 1361-1366, http://dx.doi.org/10.1016/j.msec.2016.08.044.

[40] O. Yamamoto, Y. Iida, Antifungal characteristics of spherical carbon materials with zinc oxide, J. Cerma. Soc. Jpn. 111 (2003) 614-616.

[41] J. Pasquet, Y. Chevalier, E. Couval, D. Bouvier, G. Noizet, C. Morlière, M.A. Bolzinger, Antimicrobial activity of zinc oxide particles on five micro-organisms of the challenge tests related to their physicochemical properties, Int. J. Pharm. 460 (2014) 92-100, http://dx.doi.org/10.1016/j.ijpharm.2013.10.031.

[42] M.A. Gondal, A.J. Alzahrani, M.A. Randhawa, M.N. Siddiqui, Morphology and antifungal effect of nano-ZnO and nano-Pd-doped nano-ZnO against Aspergillus and Candida, J. Environ. Sci. Health A Tox. Hazard. Subst. Environ. Eng. 47 (2012) 1413-1418, http://dx.doi.org/10.1080/10934529.2012.672384. 